\title{
The Impact of a Community-based Pilot Health Education Intervention for Older People as Caregivers of Orphaned and Sick Children as a Result of HIV and AIDS in South Africa
}

\author{
Hermien Boon • Robert A. C. Ruiter • Shegs James • \\ Bart Van Den Borne • Eka Williams • Priscilla Reddy
}

Published online: 8 October 2009

C The Author(s) 2009. This article is published with open access at Springerlink.com

\begin{abstract}
The increasing HIV and AIDS epidemic in South Africa poses a substantial burden to older people, in particular older women who mainly provide care for sick adult children and their grandchildren who have become orphaned and rendered vulnerable by the death or illness of their parents. In this study, 202 isiXhosa speaking older caregivers from Motherwell in the Eastern Cape Province of South Africa were trained to provide care for grandchildren and adult children living with HIV or AIDS. Based on a community needs assessment, a health education intervention comprising four modules was designed to improve skills and knowledge which would be used to assist older people in their caregiving tasks. Some topics were HIV and AIDS knowledge, effective intergenerational communication, providing home-based basic nursing care, accessing social services and grants, and relaxation techniques. Structured one-on-one interviews measured differences between pre-intervention and post-intervention scores among those who attended all four modules vs. those that missed one or more of the sessions. The results demonstrated that older people who participated in all four workshops perceived themselves more able and in
\end{abstract}

H. Boon $\cdot$ S. James $\cdot$ P. Reddy

Health Promotion Research and Development Unit, Medical Research Council, Cape Town, South Africa

H. Boon - R. A. C. Ruiter

Department of Work and Social Psychology, Maastricht University, Maastricht, The Netherlands

B. Van Den Borne

Department of Health Promotion and Health Education, Maastricht University, Maastricht, The Netherlands

E. Williams

Horizons, Population Council, Johannesburg, South Africa

H. Boon $(\bowtie)$

Department of Work \& Social Psychology, Faculty of Psychology,

Maastricht University, P.O. Box 616, 6200 MD Maastricht, The Netherlands

e-mail: hermien.boon@maastrichtuniversity.nl 
control to provide nursing care. The participants also showed a more positive attitude towards people living with HIV or AIDS and reported an increased level of HIV and AIDS knowledge. The results provided valuable information upon which the development of future interventions may be based and psychosocial and structural needs of the older caregivers may be addressed by relevant stakeholders.

\section{Keywords AIDS · Care-giving $\cdot \mathrm{HIV} \cdot$ Older people $\cdot$ South Africa}

In South Africa over the past few decades, the HIV and AIDS epidemic has placed a substantial burden on the older generation. Older people are left behind with the care for adult children with chronic illnesses or symptomatic HIV infection and grandchildren orphaned and made vulnerable by the death or illness of one or both of their parents. As health services are often unable to accommodate the increasing number of patients, families are faced with the task of taking care of their sick family members at home (Ndaba-Mbata and Seloilwe 2000). The emphasis on community and home-based care as a strategy for meeting the care and support needs of those infected and affected by HIV and AIDS has an impact on the psychosocial and physical well-being of older caregivers and on the care they provide.

Previous research in South Africa has shown that older people live in extended family situations with their children, grandchildren and sometimes other dependents with an average of no less than 4.58 dependents per caregiver (Boon et al. 2009a). Adult children are mostly unemployed, sick or have passed away, leaving the full care and responsibility for grandchildren in the hands of the older generation. With little or no support, older caregivers endure emotional, physical, financial and social costs that arise from their tasks (Boon et al. 2009a, b, under review; Freeman and Nkomo 2006; HelpAge International 2003; Ntozi and Nakayiwa 1999; Nyambedha et al. 2003; Reddy 2005; Schatz 2007; Ssengonzi 2007).

Older caregivers assume both productive and child-raising responsibilities, for example by assisting grandchildren with their homework, nursing sick adult children, and providing the family with financial means (Boon et al. 2009b; Chazan 2008; Marais 2005). Monthly pension grants that older people depend on are often insufficient to cover the basic needs of the entire household and older people often lack the correct documents and skills to apply for grants for their children or grandchildren (Boon et al. under review). Even though difficulties in providing care are encountered, older people care for their children and grandchildren willingly and mention love and responsibility as the main motives for taking on the caregiver role (Freeman and Nkomo 2006; Boon et al. under review; Orner 2006).

Caregivers perceive a lack of skills to provide basic care for dependents (Kipp et al. 2007; Olenja 1999; Ssengonzi 2007), while research indicates that caregiving is obstructed by the lack of training programs for family caregivers (Ndaba-Mbata and Seloilwe 2000). Also external factors such as poverty and the number of dependent children play a role in the quality of support family members are able to provide (Madhavan 2004; Ssengonzi 2007). Available support for the community often comes from resources outside the family structure and includes community-based programs (Madhavan 2004) or financial assistance schemes from the government (Department of Social Development 2003; Schatz and Ogunmefun 2007).

In a previous study we identified the predictors of older people's perceived abilities to provide care, communicate with children and grandchildren, provide income, and being able to relax (Boon et al. 2009b). That study showed that attitudes towards people living 
with HIV and AIDS, attitudes towards intergenerational communication with children and grandchildren, personal and subjective norms towards providing care, knowledge about accessing grants, and perceived control over nursing care activities were significant correlates of older people's perceived ability to handle their care-giving responsibilities. In addition, empowerment strategies to enable older people to develop their own skills and abilities to cope effectively with issues confronting them, has been proven an effective strategy for strengthening older people's interactions with their dependents (Cox 2002).

Existing intervention research on HIV and AIDS related care conducted in South Africa and Uganda has mainly focused on clinical and practical pediatric home-based care for children infected and affected by HIV or AIDS (Willis et al. 2005; Save the Children UK 2003). Research conducted in Botswana mainly focused on caring for the professional caregiver in dealing with the loss and care for HIV and AIDS infected patients (Nurses Association Botswana 2004). Besides, systematic intervention research on family caregivers of HIV or AIDS infected children has been conducted in the United States (Cox 2003; Goicoechea-Balbona 1998; Kelley et al. 2001) and in Poland (Kmita et al. 2002) with populations and settings that differ greatly from our sample. To the best of our knowledge, no existing systematic intervention research has been conducted specifically focusing on older people as caregivers in South Africa to assist them in building their capacity to take care of their dependents in the context of HIV and AIDS. Therefore, in the present paper we describe the effectiveness of a pilot community-based intervention program that aimed to address the psychosocial determinants of the perceived ability among older people to provide care for sick children and vulnerable grandchildren by using suitable strategies such as verbal persuasion and practical skills development. The objectives of the intervention program were based on previous qualitative and quantitative research (Boon et al. 2009a, b, under review) conducted among the same study population and aimed to (1) build capacity among older caregivers to provide reasonable care to sick and orphaned children and grandchildren, (2) enhance the perceived ability of older caregivers to cope with their psychosocial needs, (3) facilitate intergenerational communication between older caregivers and their dependents, including on HIV and AIDS prevention issues, and (4) facilitate the dissemination of information to older people on existing community and social support services. It was hypothesized that participation in the four modules of this health education intervention would result in more knowledge on topics associated with HIV and AIDS and a higher perceived ability to take care of sick adult children and grandchildren.

\section{Methods}

\section{Study design}

The effectiveness of the pilot intervention was tested in a longitudinal one-group study with a pretest at the start of the program, a post-test immediately after the program, and followup test three months after the end of the program. The study was conducted in Motherwell, a township in the city of Port Elizabeth in the Eastern Cape province of South Africa. Preliminary data analyses showed that not all caregivers from Motherwell completed all modules. We therefore decided to base the evaluation of the intervention not only on an analysis of baseline vs. post-test differences but also included a comparison between older caregivers in Motherwell who completed the full intervention by participating in all four 
sessions $(N=141)$ and those who did not or only partly $(N=61)$ in what can be called a quasi-experimental design. ${ }^{1}$

\section{Study setting}

The participants in this study were isiXhosa speaking people of 60 years and older who were responsible for the care for their sick children and/or (orphaned) grandchildren as a result of HIV and AIDS. Historically the Eastern Cape is home to a predominantly isiXhosa population and portrays rich cultural traditions. Motherwell consists of informal settlements and is part of the Nelson Mandela Metropolitan Municipality (NMMM). The majority of the population in the metropolitan is African, younger than 30 years old and does not have a secondary school qualification (Nelson Mandela Bay Municipality 2008).

As other informal settlements in the Eastern Cape, Motherwell is faced with high rates of unemployment, poverty and service delivery backlogs (Department of Provincial and Local Government South Africa 2005; Eastern Cape Department of Social Development 2008; Eastern Cape Provincial Government 2007). According to the latest statistics of the Department of Health in South Africa (2007), HIV-infection and AIDS are very prevalent in the Eastern Cape as $28.6 \%$ of the antenatal clinic attendees in the Eastern Cape were found to be infected with HIV in 2006. No other specific information about the HIV prevalence in Motherwell was found.

\section{Participants}

In total 209 older persons participated in the baseline interview. Five participants were excluded from the data analyses as they did not fulfill the inclusion criteria, which were: participants had to speak isiXhosa, be over the age of 60 , and look after sick or orphaned children or grandchildren. Two participants were excluded as no consent forms were found for them. This resulted in a final sample of 202 participants.

\section{Recruitment and research procedures}

As no detailed populations statistics were available in the testing area from which a probability sample could be extracted, six community health workers and three community members were approached to provide access to caregivers with whom they had worked with extensively. The community health workers and community members were employed by Age-in-Action, a local non-governmental organization and partner in this project. The recruiters were carefully selected and intensively trained and were responsible for recruiting participants, collecting baseline data, and conducting the workshops. In total six new community members were employed and trained for collecting posttest and follow-up data.

\footnotetext{
${ }^{1}$ Initially the study design comprised of a quasi-experimental controlled trial with a convenience sample of older caregivers in Motherwell as experimental group and a similar sample in Uitenhage as control group. In Motherwell caregivers were to receive the intervention program, whereas in Uitenhage caregivers were encouraged to continue their usual Age-in-Action activities. In the course of the data analysis, however, basic baseline analyses showed significant differences between the two sites. This could have been corrected for in further analyses, however also interactions between baseline measures and study site were found, indicating that the impact of the baseline measures on the post-intervention measures was different for both study conditions. Also, in Uitenhage data was collected by the same community health workers at all three time points, and therefore could have influenced the validity of the data. In Motherwell data was only collected by community health workers at baseline, and new community members were trained for the collection of post-test and follow-up data who were further blind to the contents of the workshop sessions, increasing the validity of the data collection. Therefore it was decided to exclude the data collected in Uitenhage from the study.
} 
All recruiters and interviewers were female, spoke isiXhosa as their first language and lived in the same community as the older caregivers. Through their extensive knowledge of the area and experience of working with older people through Age-in-Action, the health workers were able to access older caregivers in the community.

The recruiters approached isiXhosa speaking older caregivers of 60 years and older at their Age-in-Action club activities; they explained the aims and objectives of the study and invited them to participate. Through a snow-ball effect, other older community members became aware of the study and showed interest to participate. They were also approached by community health workers and were invited to participate if they matched the inclusion criteria.

Community health workers and members received a four-day interactive training about the implementation of the intervention. They were taught in a participatory manner how to facilitate the workshops with the older people and make a record of the sessions. Four teams were set up comprising each of one facilitator and one co-facilitator. The training sessions as well as the actual modules were conducted in isiXhosa, the first language of both the health workers and the participants. Quality control was observed by an external professional who supported the health workers on-site and was able to immediately remedy situations that arose, especially by providing on-going motivation for the health workers to maintain the desired standard of training. Besides, the external professional person was also valuable in providing emotional support and counseling for participants who were in need of sharing their experiences.

One-on-one interviews were used for data collection at all three time intervals. Questions and possible responses were read out loud to the participants and paper questionnaires were used to register responses. The interviews were conducted in isiXhosa and took place at the homes of the participants. Each interview took about one hour and twenty minutes. Detailed information about the content, procedures and confidentiality of the study was provided to the participants both verbally and in writing before consent was obtained. Ethical approval for the study was granted by the South African Medical Association Ethics Committee.

\section{The intervention}

Based on information collected in previous formative research (Boon et al. under review; Reddy 2005), a quantitative survey (Boon et al. 2009a), a focus group discussion with community health workers of Age-in-Action and interviews with senior staff of Age-inAction, possible topics for the workshops were decided upon. Also relevant parts of existing manuals and interventions that were conducted in similar settings were adjusted, and contributed to the development of the intervention (Nurses Association of Botswana 2004; Saleh-Onoya et al. 2008; Save the Children 2003; Sifunda et al. 2008; Vlok 1977; Willis et al. 2005). The workshops were based on interactive, participatory discussions and practical exercises. Factual knowledge was provided through talks and handouts. The groups consisted of 10 to 12 older participants each. The intervention consisted of four weekly workshop-sessions, each of about three hours containing a range of topics. Module 1 provided accurate information about HIV and AIDS and explored the behavior and understanding of young people of today. Module 2 addressed skills to bridge the generational communication gap between caregivers and their children and grandchildren and included topics such as how to talk about sensitive matters. Module 3 focused on skills to provide basic home-based nursing care to sick children and aimed at improving knowledge to maintain medication compliance. Module 4 explored the topic of social assistance and provided up-to date information on accessing the available support services. Besides, each workshop included a component in which practical relaxation techniques and basic exercises were trained. Please contact the first author for a detailed overview of the content of the modules. Each 
intervention objective was addressed by specific psychosocial change targets and intervention techniques (Abraham and Michie 2008), Table 1 provides an overview.

\section{Workshop participation}

Caregivers were invited to participate in all four workshops. Of the 202 participants, 141 older people completed all four workshop sessions, 13 participants did not attend all four workshops and 48 participants did not attend any workshop session at all. Reasons for non-attendance were mostly related to health problems $(N=22)$, being out of town $(N=9)$ or work responsibilities $(N=3)$. Two participants were not able to attend due to death in their families, one participant was not fully aware of the transport arrangements for attending the workshops and one participant was unable to leave her sick child alone. Two participants passed away during the course of the study and one participant was not interested in attending the workshops. For seven participants the reasons for non-attendance were unknown. All participants were provided daily with transport, tea and lunch and on completion of the training they received a gift as a token of appreciation. After completion of the workshops, an immediate post-test interview was conducted among 177 participants (response rate $=88 \%$ ), followed by a followup interview after three months among 182 participants (response rate $=90 \%$ ).

\section{Measures}

The measurement instruments were based on findings from previous qualitative and quantitative studies (Boon et al. 2009a, b, under review; Reddy 2005), existing literature about older people as providers of care, and general predictors of human behavior derived from social cognition models (Connor and Norman 2005). Demographic details included age, gender, marital status, schooling, income and number of dependents.

An overview of the measurements at baseline, immediate post-test and follow-up, including scales, sample items and Cronbach's alpha can be found in Table 2. All measurements were based on Likert-type items with three, four or five response options. Validated instruments were used to measure depression (i.e., Hopkins Symptom Checklist-25; Derogatis et al. 1974; Hesbacher et al. 1980) and ways of coping (i.e., Ways of Coping Checklist; Folkman and Lazarus 1985). Factor analysis was used to confirm the structures of existing scales and subscales. For the depression scale, all items, except two which were culturally inappropriate, were included into one scale after inspection of the scree-plot, which showed one factor. The original Ways of Coping Checklist (Folkman and Lazarus 1985) defined six subscales. In this study, factor analysis did not find the expected six subscales. After thorough inspection of the individual items and the scree-plot, the scale was divided into two subscales: proactive and passive coping (see Table 2). One item was removed from the passive coping scale as it was not appropriate in the cultural context of the sample.

For each measure, scores on items that showed sufficient internal consistency (Cronbach's alpha $[\alpha]>.60$ ) were averaged into a single index. Higher scores reflected a stronger presence of the concerning variable.

\section{Data analyses}

SPSS v15.0 (SPSS, Chicago, IL) was used to analyze the data. The analysis was stratified by baseline, post-test and follow-up. Frequency analyses were conducted to describe the demographic characteristics of the study sample at baseline and Pearson's Chi Square $\left(\chi^{2}\right)$ and $t$ tests to determine possible statistically significant differences between the 
participating and non-participating groups. Separate univariate analyses of covariance (ANCOVA) were conducted to explore the effects of the intervention at immediate post-test and 3-month follow-up respectively for those with complete participation $(N=141)$ vs. those with incomplete or no participation $(N=61)$, while controlling for baseline measures. A 5\% significance level was observed throughout. However, given the quasi-experimental design and the relative high number of outcome variables, the Bonferroni correction was used to control for multiple comparisons in the ANCOVAs resulting in an observed significance level of $<0.003$ ( 0.05 divided by $N=19$ outcome variables).

\section{Results}

Demographics and care-giving details

Most of the participants were female $(N=165 ; 81.7 \%)$, between the ages of 60 and $69(N=79$; $39.1 \%)$ and widowed $(N=115 ; 55.9 \%)$. Forty-seven $(23.3 \%)$ participants were married. A minority of the sample attended formal schooling and completed primary school. Half of the caregivers indicated that they did not receive an income at all and for those that did receive an income, it was a monthly household income of less than R1000 (approx. 120 USD at the time of the study). A small pension grant of R740 per month was the main source of income for the majority of participants. Three-quarter of the caregivers indicated to be solely responsible for their children and/or grandchildren and on average, participants cared for 4.97 dependents with the range being 1 to 15 . Forty-nine participants only cared for grandchildren, 6 participants only cared for adult children and the majority of 147 participants cared for both. The average number of years that participants cared for their dependents was 17 years $(\mathrm{SD}=8.44)$, ranging from one month to 45 years. No demographic differences were found between participants who completed all workshops and participants who did not. See Table 3 for an overview.

Impact of the workshops at immediate post-test

Table 4 provides an overview of the effectiveness of the workshops on the dependent variables at immediate post-test (T1) and at follow-up (T2). Comparisons between participants who completed all workshops and those who completed only a few or no workshops showed that at immediate post-test participants who participated in all four workshops perceived themselves more able to provide nursing care than those who did not attend all workshops $(F(1,161)=$ $19.03, p<.003)$. Furthermore, participants who took part in the complete series of workshops were more likely to have a more positive attitude towards people living with HIV or AIDS ( $F$ $(1,167)=17.12, p<.003)$; showed a higher subjective norm on providing care, indicating that they perceived the opinion of relevant others as more important $(F(1,165)=26.48, p<.003)$; perceived more control over nursing care activities $(F(1,167)=9.17, p<.003)$; and were more likely to improve their knowledge about HIV and AIDS issues $(F(1,157)=38.29, p<.003)^{2}$.

\footnotetext{
${ }^{2}$ Socio-demographic variables such as the respondent's relationship to the dependent (whether the respondents were only caring for grandchildren, adult children or both), the duration of providing care and gender of the caregiver were originally included as covariates in the analyses. The results showed a highly similar pattern of findings compared to when they were not included in the model. The limited impact of these socio-demographic covariates could be related to motives of love, responsibility (Boon et al. under review; Freeman and Nkomo 2006; Orner 2006) and strengthening kinship ties being the main reasons for taking on the role as caregiver (Muga and Onyango-Ouma 2009) in the South African large extended family systems regardless of the number of dependents and the relationship and gender of the caregiver.
} 


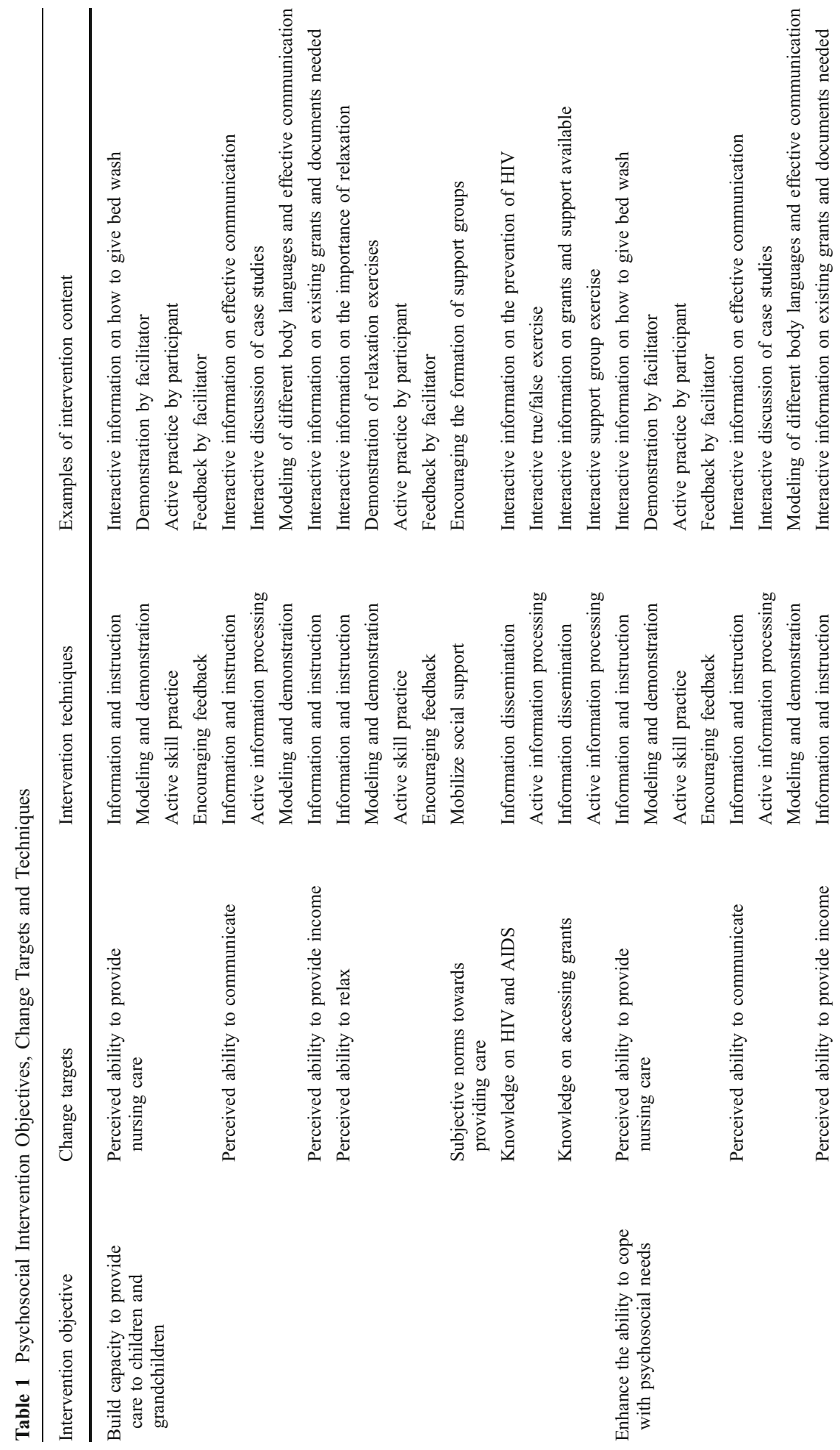



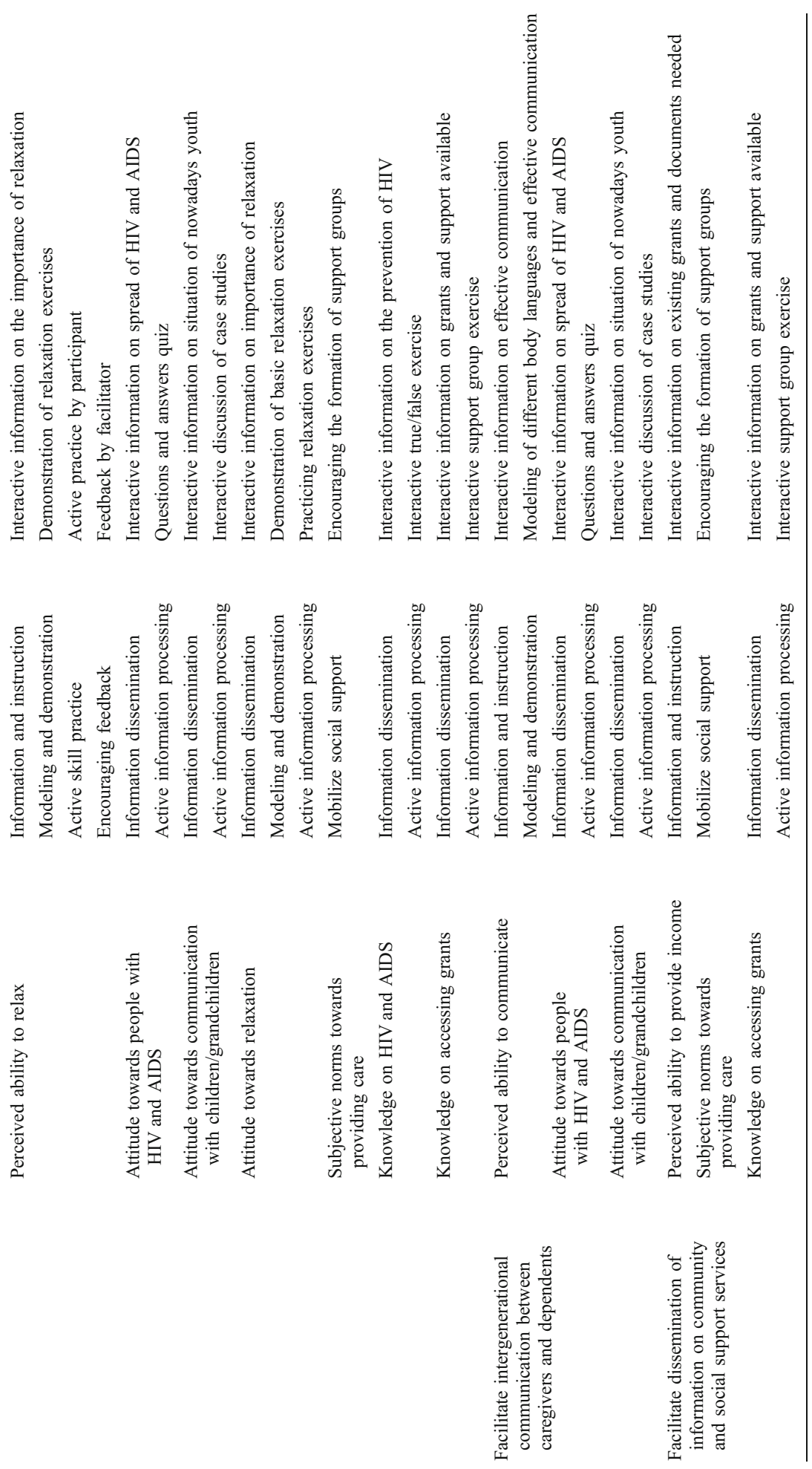


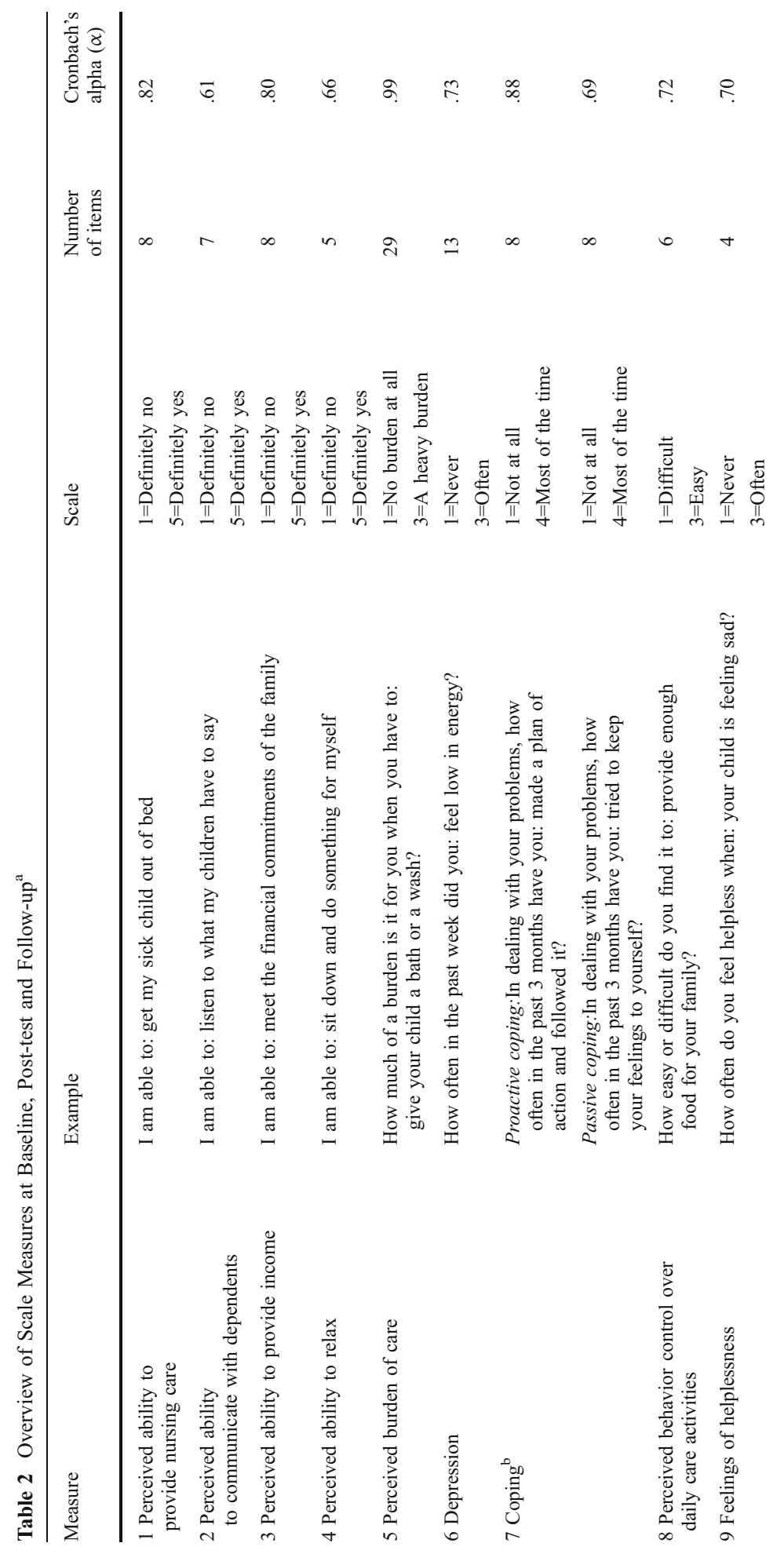




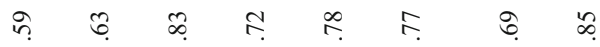
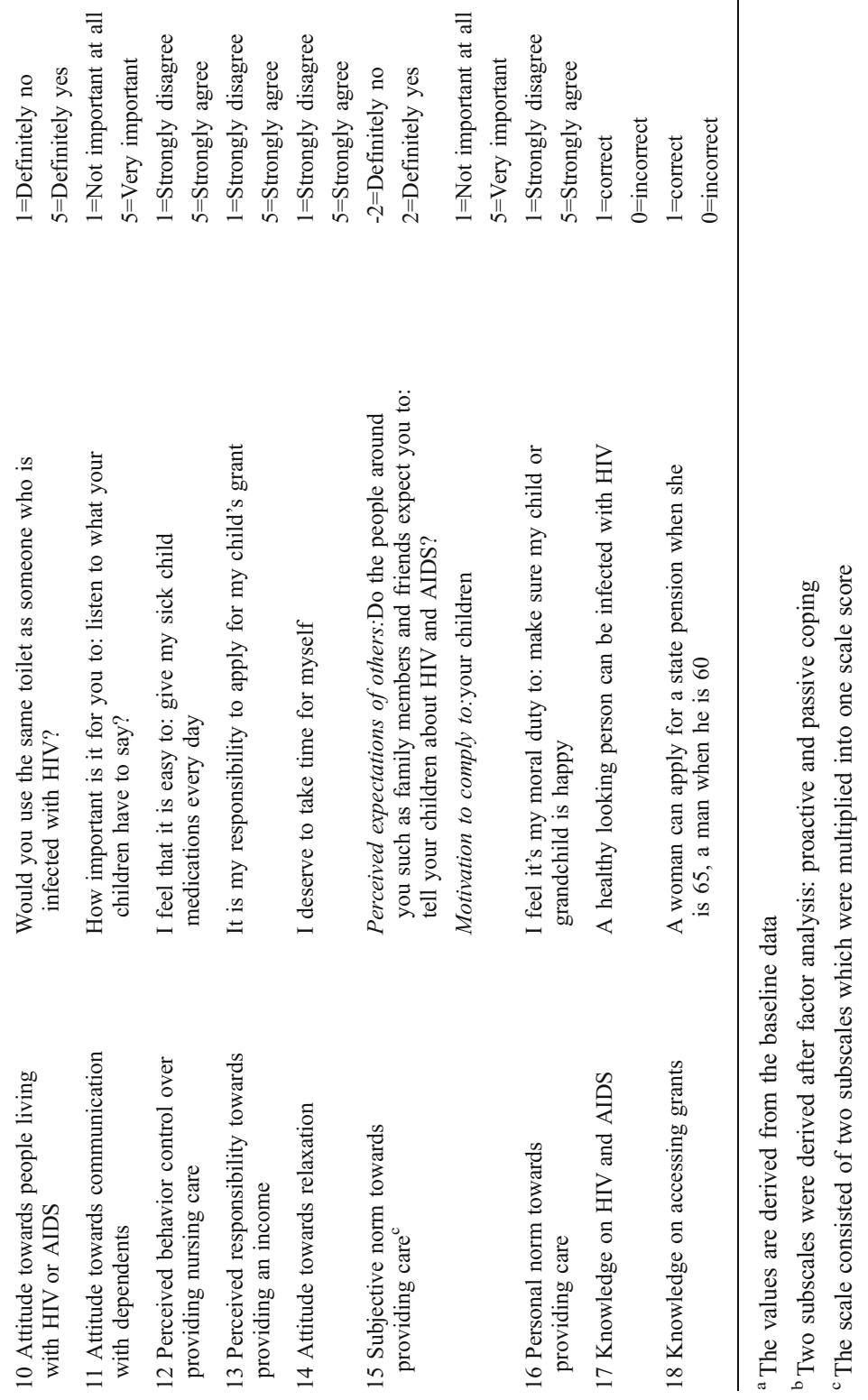
Table 3 Demographic and Caregiving Details of the Study Population $(N=202)$
Number of participants (\%)

\begin{tabular}{|c|c|}
\hline \multicolumn{2}{|l|}{ Demographic information } \\
\hline \multicolumn{2}{|l|}{ Gender } \\
\hline -Female & $165(81.7 \%)$ \\
\hline -Male & $34(16.8 \%)$ \\
\hline -Missing & $3(1.5 \%)$ \\
\hline \multicolumn{2}{|l|}{ Age } \\
\hline -Between 60 and 69 years & $79(39.1 \%)$ \\
\hline -Between 70 and 79 years & $73(36.1 \%)$ \\
\hline -Older than 80 years & $47(23.3 \%)$ \\
\hline -Missing & $3(1.5 \%)$ \\
\hline \multicolumn{2}{|l|}{ Marital status } \\
\hline -Married & $47(23.3 \%)$ \\
\hline -Single & $24(11.9 \%)$ \\
\hline -Divorced & $14(6.9 \%)$ \\
\hline -Widowed & $115(56.9 \%)$ \\
\hline -Missing & $2(1.0 \%)$ \\
\hline \multicolumn{2}{|l|}{ Formal schooling } \\
\hline -Attended & $80(39.6 \%)$ \\
\hline -Did not attend & $118(58.4 \%)$ \\
\hline -Missing & $4(2.0 \%)$ \\
\hline \multicolumn{2}{|l|}{ Highest school level complete } \\
\hline -Lower primary school & $34(16.8 \%)$ \\
\hline -Higher primary school & $31(15.3 \%)$ \\
\hline -Junior secondary school & $15(7.4 \%)$ \\
\hline -Senior secondary school & $5(2.5 \%)$ \\
\hline -Missing & $117(57.9 \%)$ \\
\hline \multicolumn{2}{|l|}{ Monthly income } \\
\hline -No income & $101(50.0 \%)$ \\
\hline -Less than R500 & $4(2.0 \%)$ \\
\hline -Between R500 and R1000 & $80(39.6 \%)$ \\
\hline -More than R1000 & $4(2.0 \%)$ \\
\hline -Missing & $13(6.4 \%)$ \\
\hline \multicolumn{2}{|l|}{ Main source of income } \\
\hline -Pension grant & $103(51.0 \%)$ \\
\hline -Unemployment benefits & $3(1.5 \%)$ \\
\hline -Disability grant & $2(1.0 \%)$ \\
\hline -Child support grant & $17(8.4 \%)$ \\
\hline -Paid job & $1(0.5 \%)$ \\
\hline \multicolumn{2}{|l|}{ Care-giving situation } \\
\hline -Number of dependents (M, SD) & $4.97(2.72)$ \\
\hline -Sole responsibility for dependents & $151(74.8 \%)$ \\
\hline
\end{tabular}




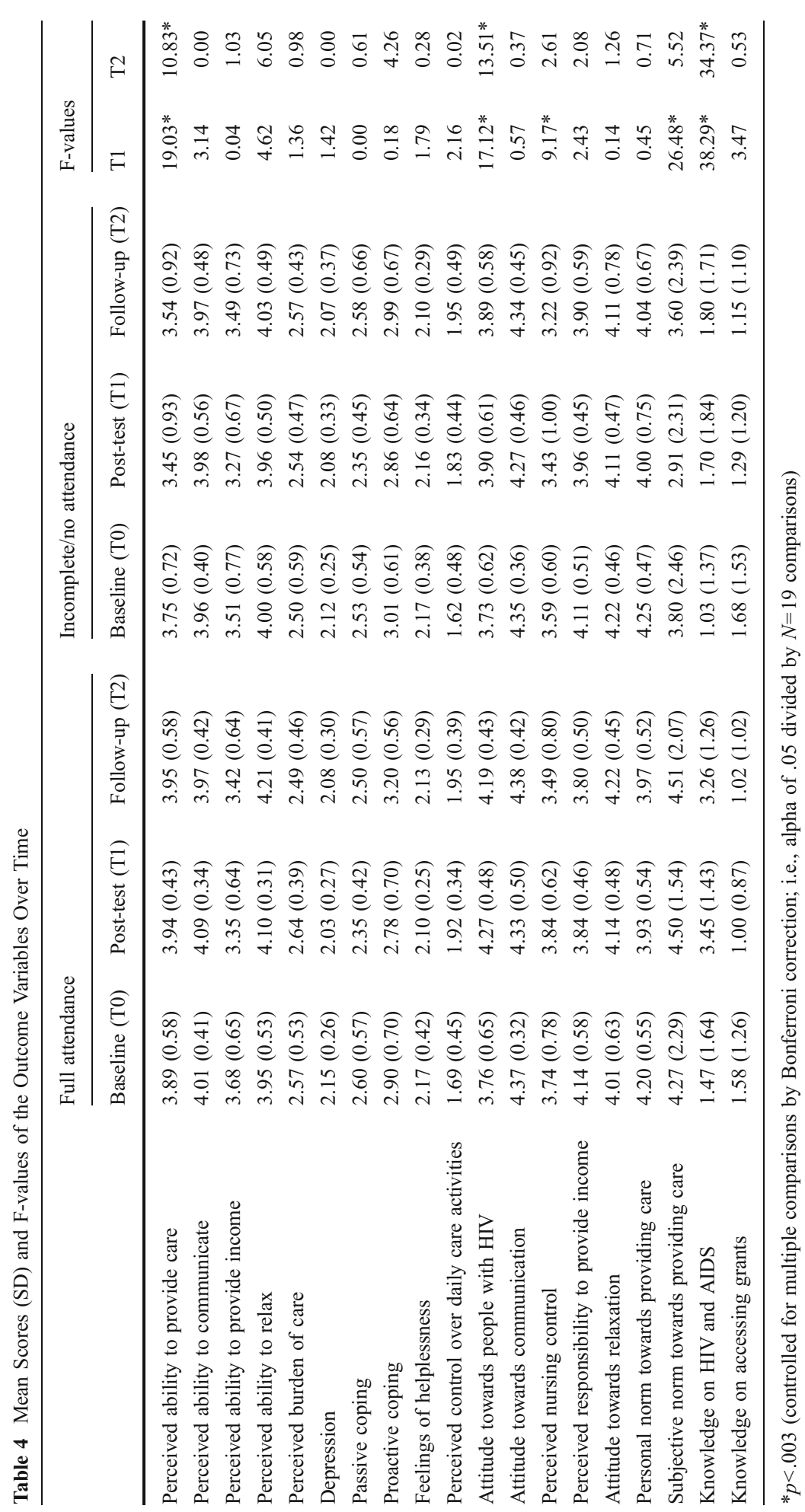


Impact of the workshops at 3-months follow-up

When comparing participants with complete and incomplete participation at follow-up, participants who attended all workshops were still more likely to perceive themselves able to provide care for their dependents compared to those who did not fully participate $(F(1,172)=$ $10.83, p<.003)$. Participants who were present at all workshops were also more likely to have a more positive attitude towards people living with $\operatorname{HIV}$ or $\operatorname{AIDS}(F(1,177)=13.51, p<.003)$. As was found in the post-test, also in the follow-up test knowledge about HIV and AIDS was higher among caregivers who completed all sessions $(F(1,166)=34.37, p<.003)$ than among those that were not present at all sessions. ${ }^{2}$

\section{Discussion}

The findings of this pilot study show that the intervention had a positive effect on assisting older caregivers in their care-giving responsibilities for those who attended all workshop sessions. The results show that some of the important problems that older people face as caregivers can be alleviated and perhaps even be prevented by an intervention such as the intervention tested here.

Participants who completed all workshops reported a more positive attitude towards people living with HIV or AIDS and showed an increased knowledge about HIV and AIDS compared to those participants with incomplete or no participation. Participants who attended all workshops were also more likely to perceive themselves able to provide care for their dependents. They reported more positive subjective norms towards providing care and a higher perceived control over nursing care activities, but only at immediate post-test compared to participants who only partly or did not participate. When not controlled for multiple comparisons and with a significance level of 5\%, caregivers who participated in all workshops showed a higher perceived ability to relax at both post-test and follow-up. Furthermore, they showed higher proactive coping skills at follow-up, and subjective norms towards providing care remained higher at follow-up.

As the results show, no changes were found for the perceived ability to communicate with children and grandchildren and attitudes towards communication. It is likely that the information, discussions and role-playing during the workshops were not sufficient to facilitate intergenerational communication. More research is needed to gain a deeper understanding of the social, cultural and historical relationships and communication processes between elders and children or grandchildren. The intervention also showed that a different approach is needed to create conditions that allow older people to improve their financial situation by accessing grants for their dependents or participate in income generating activities. The perceived ability to provide income, perceived responsibility to provide income, and knowledge to provide income reduced after participating in the study. It is therefore likely that both the provided information and the discussions during the workshops were insufficient to make participants feel confident in accessing available funds from the government. A possible reason could be that the information on accessing grants for dependents was too general and perhaps too much. Even though the information was kept as basic as possible, it might have been confusing to participants to talk about all available grants as some of the information might not have been applicable to them. Also no practical income generating skills were taught in the workshops in order to facilitate higher incomes.

The findings of this study demonstrate significant positive changes amongst older people in providing care for their children and grandchildren and highlight the need for future intervention programs addressing communication between generations, perhaps by including 
younger people in workshop sessions with their parents or grandparents and explore what they can learn from each other in order to create more understanding and respect for both the older and younger generations. In addition to disseminating information on social grants, older people should be provided with practical assistance to fill up forms and be accompanied to the social grant office when applying for grants for themselves or their dependents. Also older people should be assisted in learning practical skills for possible income generating activities, such as how to start a vegetable garden or sewing club and how to sell their products.

Community support structures should be investigated to see where they could be of any assistance to the caregivers. Also constructs already investigated and proven changeable, like knowledge on HIV and AIDS, as well as theoretical constructs such as attitudes towards people living with HIV or AIDS should be included in future programs. Any intervention targeting older people will need to be implemented in a manner that considers the socio-economic circumstances and the history of the impoverished life that they have come through. The implementation of such interventions will be strengthened by the commitment and input from different stakeholders from social development and community organizations.

As this study was conducted among a specifically selected and small group of older people in the Eastern Cape in South Africa, caution should be observed in generalizing results to other populations. Also the results may not be representative to all older people in Motherwell as only caregivers that were known and visible to the community were recruited for participation in the study. This might have resulted in an over-representation of active older caregivers who were able to cope better with their care-giving responsibilities as they had access to community support services such as Age-in-Action. The absence of a control group makes it impossible to attribute the changes observed in our study population solely to the pilot intervention program. Although no significant differences of demographic variables were found between participants who fully attended the workshops and those who did not, confounding may have taken place based on unknown variables (e.g., community structure, the availability and accessibility of support) that determined the attendance in the workshops, as well as the results of the intervention. Finally, due to financial and practical limitations this study did not include measures of the targeted behaviors. The study restricted itself to measuring the perceived ability to undertake carerelevant behaviors. Although social cognition models of human behavior (e.g., Theory of Planned Behavior, Ajzen 1991) indicate perceived ability and actual coping skills as important determinants of behavior (Godin and Kok 1996), future studies should be extended with measures of actual behavior either through self-report or observation.

In conclusion, the findings have added important information to the current understanding of the effectiveness of targeted community based intervention programs and demonstrate that through the intervention older caregivers felt better able to provide care for their sick adult children and grandchildren. However, more case studies are needed to confirm our findings and extend the knowledge base of intervention programs to assist older people to provide care in the context of HIV and AIDS. Also, further research and in particular the development of programs that focus on intergenerational communication and structural needs, such as financial assistance and income generation to assist older caregivers of sick adult children and grandchildren with their heavy tasks is urgently needed.

Acknowledgements The authors wish to thank the Age-in-Action staff, community health workers, the older people of Motherwell and Uitenhage in the Eastern Cape of South Africa for their support and cooperation in this project. This study was funded by Horizons Program, Population Council under subagreement number: A104.17A. 
Open Access This article is distributed under the terms of the Creative Commons Attribution Noncommercial License which permits any noncommercial use, distribution, and reproduction in any medium, provided the original author(s) and source are credited.

\section{References}

Abraham, C., \& Michie, S. (2008). A taxonomy of behavior change techniques used in interventions. Health Psychology, 27, 379-387.

Ajzen, I. (1991). The Theory of Planned Behavior. Organizational Behavior and Human Decision Processes, $50,179-211$.

Boon, H., Ruiter, R. A. C., James, S., Van den Borne, B., Williams, E. \& Reddy, P. (2009a). Correlates of grief among older people caring for children and grandchildren as a result of HIV and AIDS in South Africa. Aging \& Health.

Boon, H., James, S., Ruiter, R. A. C., Van den Borne, B., Williams, E. \& Reddy, P. (2009b). Explaining perceived ability among older people to provide care as a result of HIV and AIDS in South Africa. AIDS Care.

Boon, H., James, S., Ruiter, R. A. C., Van den Borne, B., Williams, E. \& Reddy, P. (under review). Challenges for older caregivers in a time of HIV and AIDS: A qualitative analysis.

Chazan, M. (2008). Seven 'deadly' assumptions: Unravelling the implications of HIV/AIDS among grandmothers in South Africa and beyond. Ageing \& Society, 28, 935-958.

Connor, M., \& Norman, P. (2005). Predicting health behaviour: A social cognition approach. In M. Connor \& P. Norman (Eds.), Predicting health behaviour: Research and practice with social cognition models. Berkshire, UK: Open University Press.

Cox, C. (2002). Empowering African American custodial grandparents. Social Work, 47, 45-54.

Cox, C. (2003). Designing interventions for grandparent caregivers: the need for an ecological perspective for practice. Families in Society, 84, 127-134.

Department of Health, South Africa. (2007). National HIV and Syphillis Antenatal Sero-Prevalence Survey in South Africa 2006. Directorate Health Systems Research, Research Coordination \& Epidemiology.

Department of Provincial and Local Government South Africa. (2005). Motherwell Urban Renewal Programme. Available online at: http://www.thedplg.gov/za/urp/Reports/Cabinet\%20Lekgotla/Mother wellv2.pdf [03.11.2008].

Department of Social Development, South Africa. (2003). Fact sheet: Social grants beneficiaries. Available online at http://www.welfare.gov.za/Documents/2003/Budget\%20Vote/Fact\%20Sheets/benf.pdf [03.11.2008].

Derogatis, L. R., Lipman, R. S., Richels, E. H., Uhlenhuth, E. H., \& Covi, L. (1974). The Hopkins Symptom Checklist (HSCL).A self-report system inventory. Behavioral Science, 19, 1-15.

Eastern Cape Department of Social Development. (2008). Socio-economic \& demographic profile: Nelson Mandela Metropole. Available online at http://www.socdev.ecprov.gov.za/statistics/demographics/ nelson-mandela area info.htm [29.09.2008].

Eastern Cape Provincial Government (2007). The Nelson Mandela Metropolitan District. Available online at http://www.ecprov.gov.za/page.php?index=12 [30.10.2007].

Folkman, S., \& Lazarus, R. S. (1985). If it changes it must be a process: Study of emotion and coping during three stages of a college examination. Journal of Personality and Social Psychology, 48, 150-170.

Freeman, M., \& Nkomo, N. (2006). Guardianship of orphans and vulnerable children. A survey of current and prospective South African caregivers. AIDS Care, 18, 302-310.

Godin, G., \& Kok, G. (1996). The theory of planned behavior: a review of its applications to health related behaviors. American Journal of Health Promotion, 11, 87-98.

Goicoechea-Balbona, A. (1998). Children with HIV/AIDS and their families: a successful social work intervention based on the culturally specific health care model. Health \& Social Work, 23, 6169.

HelpAge International. (2003). Policy report: Forgotten families - Older persons as carers of orphans and vulnerable children. Brighton: International HIV/AIDS Alliance.

Hesbacher, P. T., Rickels, K., Morris, R. J., Newman, H., \& Rosenfeld, H. (1980). Psychiatric illness in family practice. Journal of Clinical Psychiatry, 41, 6-10.

Kelley, S. J., Yorker, B. C., Whitley, D. M., \& Sipe, T. A. (2001). A multimodal intervention for grandparents raising grandchildren: Results of an exploratory study. Child Welfare, 80, 27-50.

Kipp, W., Tindyebwa, D., Karamagi, E., \& Rubaale, T. (2007). How much should we expect? Family caregiving of AIDS patients in rural Uganda. Journal of Transcultural Nursing, 18, 358-365. 
Kmita, G., Baranska, M., \& Niemiec, T. (2002). Psychosocial intervention in the process of empowering families with chilren living with HIV/AIDS - a descriptive study. AIDS Care, 14, 279-284.

Madhavan, S. (2004). Fosterage patterns in the age of AIDS: continuity and change. Social Science \& Medicine, 58, 1443-1454.

Marais, H. (2005). Buckling: the impact of AIDS in South Africa. Pretoria: University of Pretoria Press.

Muga, G. O. \& Onyango-Ouma, W. (2009). Changing household composition and food security among the elderly caretakers in rural western Kenya. Journal of Cross Cultural Gerontology. Available online at http://www.springerlink.com/content/x2345u8176u84525/fulltext.pdf [29.07.2009].

Ndaba-Mbata, R. D., \& Seloilwe, E. S. (2000). Home-based care of the terminally ill in Botswana: knowledge and perceptions. International Nursing Review, 47, 218-223.

Nelson Mandela Bay Municipality. (2008). Integrated Development Plan 2008 - 2012 of the Nelson Mandela Bay Metropolitan Municipality. Available online at http://www.nelsonmandelabay.gov.za/ Documents.aspx?objID=85\&cmd=download \&docID=487 [03.11.2008].

Ntozi, J. P. M., \& Nakayiwa, S. (1999). AIDS in Uganda: how has the household coped with the epidemic? The continuing African HIV/AIDS epidemic. Canberra: Health Transition Centre, National Centre for Epidemiology and Population Health, Australian National University.

Nurses Association of Botswana. (2004). Caring for the caregivers. Cape Town: Policy Project.

Nyambedha, E. O., Wandibba, S., \& Aagaard-Hansen, J. (2003). "Retirement lost" — the new role of the elderly as caretakers for orphans in Western Kenya. Journal of Cross-Cultural Gerontology, 18, 33-52.

Olenja, J. M. (1999). Assessing community attitude towards home-based care for people with AIDS (PWAS) in Kenya. Journal of Community Health, 24, 187-199.

Orner, P. (2006). Psychosocial impacts on caregivers of people living with AIDS. AIDS Care, 18, 236-240.

Reddy, P. (2005). 'Inkala ixinge etyeni: Trapped in a difficult situation'. The burden of care on the elderly in the Eastern Cape, South Africa. Horizons Research Update. Johannesburg: Population Council.

Saleh-Onoya, D., Braxton, N. D., Sifunda, S., Reddy, P., Ruiter, R., Van den Borne, B., et al. (2008). SISTA South Africa: the adaptation of an efficacious HIV prevention trial conducted with African-American women for isiXhosa-speaking South African women. Journal of Social Aspects of HIV/AIDS, 5, 186191.

Save the Children UK. (2003). Care for children infected and those affected by HIV/AIDS. A handbook for community health workers. Kampala, Uganda: Save the Children UK.

Schatz, E. J. (2007). "Taking care of my own blood": older women's relationships to their households in rural South Africa. Scandinavian Journal of Public Health, 35(S69), 147-154.

Schatz, E., \& Ogunmefun, C. (2007). Caring and contributing: The role of older women in rural South African multi-generational households in the HIV/AIDS era. World Development, 35, 1390-1403.

Sifunda, S., Reddy, S. P., Braithwaite, R. B., Stephens, T., Bhengu, S., Ruiter, R. A. C., et al. (2008). The effectiveness of a peer-led HIV/AIDS and STI health education intervention for prison inmates in South Africa. Health Education and Behavior, 35, 494-508.

Ssengonzi, R. (2007). The plight of older persons as caregivers to people infected/affected by HIV/AIDS: evidence from Uganda. Journal of Cross-Cultural Gerontology, 22, $19-42$.

Vlok, M. E. (1977). Manual of basic nursing care. Johannesburg: Juta \& Company, Ltd.

Willis, N., McGilvray, M., McNally, L. \& Pawinski, R (2005). Paediatric palliative care manual for home base carers. Available online at: http:/www.aidsmap.com/en/docs/77989B86-BA72-4ABF-B70C7A7F2543AD2B.asp [07.06.2006]. 